\title{
THE EFFECTS OF DIISOPROPYLFLUOROPHOSPHONATE IN SCHIZOPHRENIA AND MANIC DEPRESSIVE PSYCHOSIS
}

\author{
BY \\ DONALD W. ROWNTREE, SAMUEL NEVIN, and ANDREW WILSON \\ From the Department of Pathology of Mental Disease, Institute of Psychiatry, Maudsley Hospital, London, \\ and the Department of Applied Pharmacology, University College Hospital \\ Medical School, London
}

Diisopropylfluorophosphonate (DFP) is a drug which has been made available for physiological and pharmacological investigation as a result of researches carried out on the alkylfluorophosphonates by McCombie and Saunders (1946) for the Ministry of Supply. The anticholinesterase action of these compounds was recognized in 1941 by Adrian, Feldberg, and Kilby (1947). Later, Mackworth and Webb (1948) showed that DFP was the most active of such compounds, its anticholinesterase activity being 30 times that of eserine from which it also differs in inhibiting the enzyme irreversibly. DFP produces, in animals and man, effects similar to the muscarinic and nicotinic actions of acetylcholine. In addition Grob and others 1947(b)) have described electroencephalographic (EEG) changes in man and also mental symptoms such as tremulousness, insomnia, and confusion. These have been attributed to an anticholinesterase action of the drug on the central nervous system. On this account, it was decided to study the effect of the drug in patients with characteristic functional psychoses, to determine its influence, if any, on the mental state of these cases, and to observe whether the physical and EEG changes produced differed from those previously reported in normal subjects.

DFP dissolved in peanut oil was administered by intramuscular injection to 17 cases of schizo- phrenia and 9 cases of manic depressive psychosis. The schizophrenic group consisted of five paranoid, nine hebephrenic, one simple, and two catatonic patients. Of the manic depressives six were hypomanic, one was depressed, and two were in a state of remission. Data on age, weight, and duration of illness are presented in Table I.

Thirteen schizophrenics and nine manic depressives were given a total dosage of $13 \mathrm{mg}$. of DFP over a period of seven days $(1 \mathrm{mg}$. on the first day, $2 \mathrm{mg}$. on each succeeding day). The drug was also administered to the remaining four schizophrenics over a longer period, averaging 37 days, using a mean total dosage of $43 \mathrm{mg}$.

To assist in evaluating the results obtained in the psychotic patients an attempt was made to administer an equivalent dosage of the drug to 10 normal subjects, but in six of these not more than $7 \mathrm{mg}$. could be given because of severe symptoms. The administration of large doses of atropine to the remaining four subjects considerably reduced the incidence of these symptoms, but it was possible to give the total dosage of $13 \mathrm{mg}$. to two subjects only, the others tolerating 11 and $7 \mathrm{mg}$. respectively.

Regular psychiatric, physical, and EEG examinations were carried out during the investigation and estimations were made of the true and pseudocholinesterase activity of the venous blood.

TABLE I

ANALYSIS OF AGE, WEIGHT, AND DURATION OF ILLNESS

\begin{tabular}{|c|c|c|c|c|c|c|c|c|c|}
\hline \multirow{2}{*}{\multicolumn{3}{|c|}{ Patients }} & \multirow{2}{*}{$\begin{array}{l}\text { No. of } \\
\text { Cases }\end{array}$} & \multicolumn{2}{|c|}{$\begin{array}{c}\text { Age } \\
\text { (Years) }\end{array}$} & \multicolumn{2}{|c|}{$\begin{array}{l}\text { Weight } \\
\text { (lb.) }\end{array}$} & \multicolumn{2}{|c|}{$\begin{array}{c}\text { Duration of Illness } \\
\text { (Years) }\end{array}$} \\
\hline & & & & Range & Mean & Range & Mean & Range & Mean \\
\hline Schizophrenic $\ldots$ & $\ldots$ & $\ldots$ & 17 & $28-42$ & 37 & $94-161$ & 126 & $2-21$ & 12 \\
\hline Manic Depressive & $\cdots$ & $\cdots$ & 9 & $24-54$ & 41 & $78-146$ & 129 & $0 \cdot 2-21$ & 10 \\
\hline Controls & $\ldots$ & $\ldots$ & 10 & $18-43$ & 27 & $123-168$ & 139 & - & - \\
\hline
\end{tabular}


Cholinesterase Activity in the Plasma and Red Blood Cells

The blood cholinesterase activity of 13 schizophrenic patients, 9 manic depressive patients, and 10 normal subjects was determined before and during the administration of DFP.

Method.-Specimens of blood obtained by venipuncture were transferred to bottles containing heparin as an anti-coagulant and centrifuged. The plasma was separated, and the red cells, after being washed twice with normal saline, were laked with distilled water. The cholinesterase activity of each specimen of plasma and of red cells was determined in duplicate by the manometric technique at $38^{\circ} \mathrm{C}$, , using the specific substrates benzoyl-choline chloride for plasma and acetyl- $\beta$-methylcholine chloride for red cells, according to the method of Mendel, Mundell, and Rudney (1943). Cholinesterase activity is expressed as the amount of $\mathrm{CO}_{2}$ in $\mu 1$ liberated from $1 \mathrm{ml}$. of plasma or preparation of red cells in 60 minutes.

Pre-treatment Values of Cholinesterase Activity.The range and mean value obtained for each group of subjects are shown in Table II. Although the range of true cholinesterase activity in the red cells of the manic depressive patients is greater than in the other two groups, there is no statistically significant difference between the mean values for each group.
The range of plasma pseudo-cholinesterase activity in the three groups of subjects varied widely and in the manic depressive patients appeared to reach a higher level than in the other two groups. Statistical analysis of the results, however, showed no significant difference between the mean values for each group. One normal subject had a high level (3265) which was confirmed by repeated examinations; this subject did not exhibit any abnormal clinical signs or symptoms. His EEG, however, showed abnormalities similar to those commonly found in epilepsy.

Inhibition of Cholinesterase Activity by DFPIt will be seen (Table III) that in both schizophrenic and manic depressive patients the pseudo-cholinesterase activity of the plasma was almost completely inhibited. There was a slightly greater inhibition of true cholinesterase activity in the schizophrenic patients but the difference between the mean values for the two groups is not statistically significant.

For the purposes of comparing the effects of the drug on the schizophrenic and manic depressive patients, the inhibition of cholinesterase activity was assumed to be equivalent in each group.

In the normal subjects, irrespective of the ultimateo dose of DFP, the pseudo-cholinesterase activity was almost completely inhibited (range 76 per cent. to 100 per cent., mean 93 per cent.). The inhibition

TABLE II

CHOLINESTERASE ACTIVITY OF PLASMA AND RED BLOOD CELLS OF NORMAL SUBJECTS AND PATIENTS WITH SCHIZOPHRENIA AND MANIC DEPRESSIVE PSYCHOSIS

\begin{tabular}{|c|c|c|c|c|c|c|c|c|}
\hline \multirow{2}{*}{\multicolumn{5}{|c|}{ Patients }} & \multicolumn{4}{|c|}{ Cholinesterase Activity $\left(\mu \mathrm{l} . \mathrm{CO}_{2} / \mathrm{ml} . / 60 \mathrm{mins}\right.$.) } \\
\hline & & & & & \multicolumn{2}{|c|}{ True (Red Cells) } & \multicolumn{2}{|c|}{ Pseudo (Plasma) } \\
\hline & & & & No. & Range & Mean & Range & Mean \\
\hline Normal subjects & ... & $\ldots$ & $\ldots$ & 10 & $1681-2268$ & 1967 & $1146-3265$ & 1898 \\
\hline Schizophrenic ... & $\ldots$ & $\ldots$ & $\ldots$ & 13 & $1268-2257$ & 1811 & $842-2375$ & 1550 \\
\hline Manic depressive & $\ldots$ & $\ldots$ & $\ldots$ & 9 & $746-2223$ & 1729 & $1556-2292$ & 1966 \\
\hline
\end{tabular}

TABLE III

PERCENTAGE INHIBITION OF CHOLINESTERASE ACTIVITY OF PLASMA AND RED BLOOD CELLS OF PATIENTS WITH SCHIZOPHRENIA AND MANIC DEPRESSIVE PSYCHOSIS PRODUCED BY ADMINISTRATION OF A TOTAL DOSE OF 13 MG. DFP

\begin{tabular}{|c|c|c|c|c|c|c|c|c|}
\hline \multirow{2}{*}{\multicolumn{5}{|c|}{ Patients }} & \multicolumn{4}{|c|}{ Percentage Inhibition of Cholinesterase Activity } \\
\hline & & & & & \multicolumn{2}{|c|}{ True (Red Cells) } & \multicolumn{2}{|c|}{ Pseudo (Plasma) } \\
\hline & & & & No. & Range & Mean & Range & Mean \\
\hline Schizophrenic ... & $\ldots$ & .. & ... & 13 & $60-90$ & 79 & $86-98$ & 94 \\
\hline Manic depressive & $\ldots$ & $\ldots$ & ... & 9 & $58-84$ & 74 & $91-100$ & 98 \\
\hline
\end{tabular}


of true cholinesterase, however, varied with the dosage of DFP. In one case after $5 \mathrm{mg}$. the inhibition was 43 per cent.; in five cases given $7 \mathrm{mg}$. it ranged from 50 per cent. to 63 per cent., whereas in the remaining four subjects who received $11-13 \mathrm{mg}$. DFP the true cholinesterase was inhibited 80 per cent.

\section{Discussion}

Jones and Stadie (1939) have claimed that both schizophrenic and manic depressive patients show a tendency to have lower values for serum cholinesterase activity than normal subjects. Randall and Jellinek (1939) however did not consider that there was any significant difference between the mean values in patients with schizophrenia and those in normal subjects. The unit of activity which was measured by these and other earlier workers is not comparable with the unit of activity which we have used, since they employed acetylcholine chloride as substrate, while we have used benzoylcholine chloride, a substrate specific for pseudo-cholinesterase. A direct comparison of numerical values is therefore not valid.

In the present investigation, however, our findings of equivalent values of plasma pseudo-cholinesterase activity in psychotic patients and normal subjects are in keeping with the main conclusions of Randall and Jellinek (1939). We have in addition shown that both in schizophrenic and manic depressive patients the true cholinesterase activity of red cells is within normal limits.

DFP produced very substantial changes in the blood cholinesterase activity of these patients. It is important to emphasize that these changes were comparable in both psychotic groups, since in some respects the clinical effects of the drug were different in the two groups.

\section{General Physical Changes}

Psychotic Patients.-There were wide individual differences in the time of onset and severity of the physical symptoms produced by the drug. In general they were most marked five to eight hours after each injection but increased cumulatively. The incidence of the more important symptoms is shown in Table IV. Anorexia and nausea were the first symptoms to appear, and vomiting usually followed within 24 to 48 hours. These effects persisted for one to two days after the withdrawal of the drug. Diarrhœa was generally very slight when it occurred and there was no abdominal pain.

Pallor and subjective sensations of faintness occurred frequently, and in cases in which these symptoms were marked, fainting attacks occurred which tended to be precipitated by the sudden assumption of the erect posture. Changes in blood pressure were significantly different in the two psychotic groups. In all the manic depressive patients, except the two patients who were mentally normal at the time of the investigation, there was a gradual fall of blood pressure from the beginning of the injection period, until approximately seven days after the withdrawal of the drug. In the schizophrenic patients, on the other hand, there was a tendency for the blood pressure to rise (Fig. 1). No schizophrenic patient showed a progressive fall in blood pressure and no manic depressive patient a progressive rise. These changes in blood pressure were not associated with any significant alterations in pulse rate. In four cases the pulse became irregular, and electrocardiograms showed this to be due in two cases to auricular fibrillation and in the other two cases to ventricular extrasystoles. The auricular fibrillation was not affected by administration of atropine sulphate gr. $1 / 100(3 / 4 \mathrm{mg}$.) three times daily. In one patient not showing any cardiac irregularity there was marked reduction in the amplitude of the $P$ wave.

In five schizophrenic patients, and in the two male manic depressive cases, a slight fall in rectal temperature $\left(0.5^{\circ}\right.$ to $1.5^{\circ} \mathrm{F}$.) was observed during administration of the drug and for several days after its

TABLE IV

INCIDENCE OF CHIEF “ MUSCARINIC" SYMPTOMS IN CASES RECEIVING DFP FOR 7 DAYS

\begin{tabular}{|c|c|c|c|c|c|c|c|c|c|c|c|}
\hline \multicolumn{8}{|c|}{ Physical Signs or Symptoms } & \multicolumn{2}{|c|}{$\begin{array}{c}\text { Manic Depressives } \\
(9 \text { cases })\end{array}$} & \multicolumn{2}{|c|}{$\begin{array}{l}\text { Schizophrenics } \\
\text { (13 cases) }\end{array}$} \\
\hline $\begin{array}{l}\text { Anorexia } \\
\text { Vomiting } \\
\text { Diarrhoea }\end{array}$ & $\begin{array}{l}\ldots \\
\ldots \\
\cdots\end{array}$ & $\begin{array}{l}\cdots \\
\cdots \\
\cdots\end{array}$ & $\begin{array}{l}\cdots \\
\cdots \\
\cdots\end{array}$ & $\begin{array}{l}\cdots \\
\cdots \\
\cdots\end{array}$ & $\begin{array}{l}\cdots \\
\cdots \\
\cdots\end{array}$ & $\begin{array}{l}\cdots \\
\cdots \\
\cdots\end{array}$ & $\begin{array}{l}\cdots \\
\cdots \\
\cdots\end{array}$ & $\begin{array}{l}9 \text { cases } \\
9 \text {,, } \\
2 \text {,", }\end{array}$ & $\begin{array}{r}100 \% \\
100 \% \\
22 \%\end{array}$ & $\begin{array}{l}9 \text { cases } \\
9 \text {," } \\
1 \%\end{array}$ & $\begin{array}{r}69 \% \\
69 \% \\
8 \%\end{array}$ \\
\hline \multicolumn{6}{|c|}{ Total with gastrointestinal symptoms } & $\cdots$ & $\cdots$ & 9, & $100 \%$ & 9, & $69 \%$ \\
\hline $\begin{array}{l}\text { Pallor } \\
\text { Fainting } \\
\text { Electrocard }\end{array}$ & $\begin{array}{l}\ldots \\
\text { diogr }\end{array}$ & $\begin{array}{r}\ldots \\
\text { phic }\end{array}$ & $\begin{array}{c}\ddot{\ldots} \\
\text { anges }\end{array}$ & $\begin{array}{l}\cdots \\
\cdots \\
\cdots\end{array}$ & $\begin{array}{l}\cdots \\
\cdots \\
\cdots\end{array}$ & $\begin{array}{l}\cdots \\
\cdots \\
\cdots\end{array}$ & $\begin{array}{l}\cdots \\
\cdots \\
\cdots\end{array}$ & $\begin{array}{l}9 \\
4 \quad " \\
4\end{array}$ & $\begin{array}{r}100 \% \\
44 \% \\
44 \%\end{array}$ & 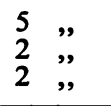 & $\begin{array}{l}38 \% \\
15 \% \\
15 \%\end{array}$ \\
\hline \multicolumn{6}{|c|}{ Total with cardiovascular symptoms } & $\ldots$ & $\ldots$ & 9 ", & $100 \%$ & 5, & $38 \%$ \\
\hline
\end{tabular}


withdrawal. Sweating was occasionally observed, increased salivation was common, and a large number of cases complained spontaneously of a

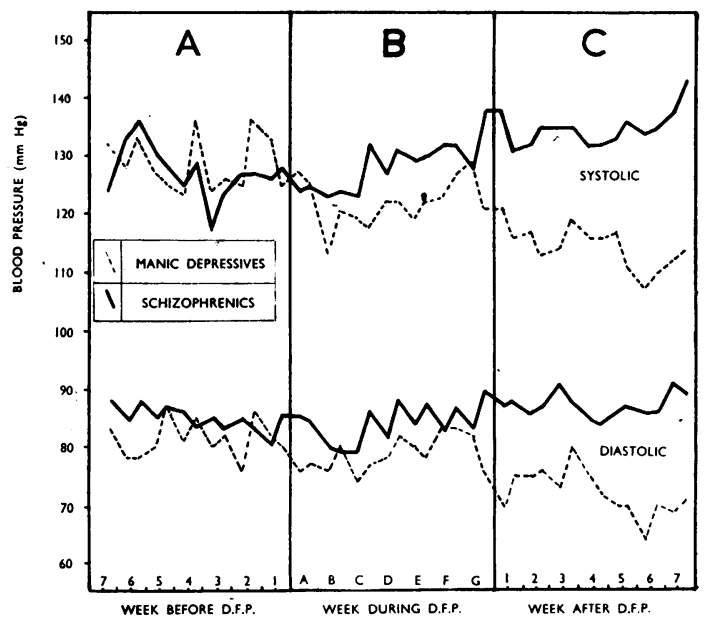

FIG. 1.-Mean systolic and diastolic blood pressures of 13 schizophrenic and 9 manic depressive patients taken twice daily during the injection period (B) and for 7 days before (A) and after (C). Statistical analysis by comparison of the differences between pre- and post-treatment mean blood pressures, and by a non-parametric test of trend has shown the divergence in these curves to be significant.

periodic "welling up" of saliva into the mouth. Lachrymation and miosis were only seen when the drug was administered over a much longer period. Records were kept of the fluid intake and output of 13 patients receiving DFP for seven days. Of these, nine had a reduced output of urine (Fig. 2). This was not directly associated with vomiting or diarrhœa and occurred in four patients who showed neither of these symptoms. The excretion of chlorides in the urine was diminished during treatment, and was increased above normal after the withdrawal of the drug. The four patients who were given DFP for 35-40 days exhibited bloating of the skin of the face associated with slight pitting ; in two there was marked œedema of the periorbital tissues, and in one pitting of the ankles was observed ; there was no evidence of cardiac failure, and examination of the urine revealed no abnormality. In three of these patients a prolonged polyuria occurred from 5 to 20 days after withdrawing the drug (Fig. 3).

In five of the nine female patients there was an increase in both the amount and frequency of menstruation. One patient menstruated intermittently for 18 days in one cycle, and another aged 51, whose menopause had occurred five years previously, had a period lasting four and a half days during treatment with the drug. A moderate rise in fasting capillary blood sugar occurred in eight of ten cases examined ; the mean value for the ten cases increased by $10 \mathrm{mg}$., 89 to $99 \mathrm{mg}$. per $100 \mathrm{c.cm}$. Insulin tolerance test results were not significantly modified, the slope of the blood sugar curve remaining essentially unchanged. The basal metabolic rate of the four schizophrenic cases under prolonged administration of the drug showed no significant change.

Generalized muscular fasciculations especially marked in the limbs were seen in 80 per cent. of all subjects studied. Their incidence did not appear to be directly related to the level of inhibition of cholinesterase or to the degree of general toxicity. Loss of tendon reflexes and hypotonia without demonstrablemuscular weakness were also commonly observed. These neuromuscular changes occurred equally in the manic depressive, schizophrenic, and normal subjects.

Normal Subjects.-The early appearance of severe gastro-intestinal symptoms in the normal subjects necessitated withdrawal of the drug and precluded adequate comparison with the effects produced in the psychotic patients. The general response to the drug, however, was similar to that observed in the psychotic patients, but, with the dosage given and despite the severe nausea and vomiting, no definitem

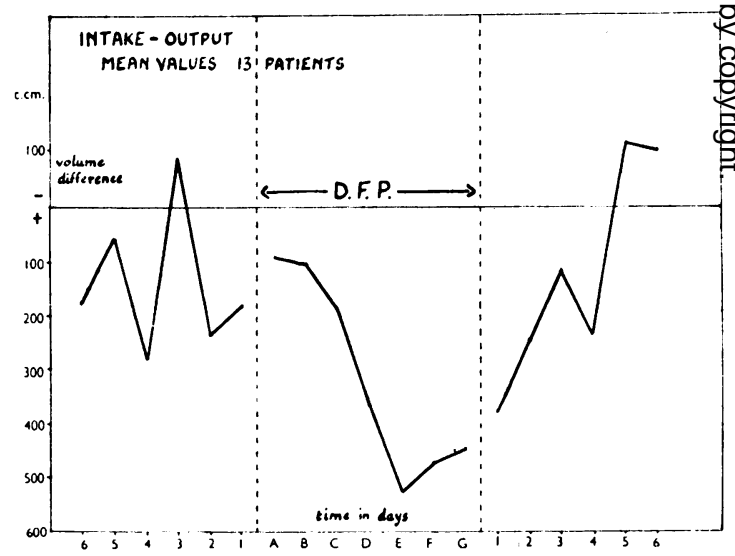

FIG. 2.-Fluid retention in cases receiving DFP for 7 days. Mean daily values (c.cm.) for the difference between fluid intake and output are plotted and fluid retention during DFP treatment is indicated by a marked fall below the line.

trends in blood pressure were seen, either during or following the injection period.

In the four cases given atropine (up to $5 \mathrm{mg}$ four-hourly) in conjunction with DFP, the effects of the latter drug were partially or completely counteracted during the period from 20 minutes to 3 hours after an injection of atropine. The effective- 
ness of atropine diminished as the cumulative effects of DFP became apparent, but these cases were able to tolerate a larger total dose of DFP than the other normal subjects. Although the characteristic effects of DFP were observed when atropine was withheld for 12 hours and also during the postinjection 7-day period, there were no significant changes in blood pressure.

\section{Discussion}

Although the schizophrenic and manic depressive patients received the same total dosage of DFP and showed comparable cholinesterase inhibition, both the incidence and severity of the muscarinic effects were considerably less in the schizophrenic group (Table IV). The remarkable tolerance to the drug exhibited by certain schizophrenic patients is exemplified by one patient who received a total dosage of $63 \mathrm{mg}$. of DFP during 35 days, without showing any characteristic effects of the drug. These observations are in keeping with the concept of "autonomic hyporeactivity" in chronic schizophrenia, particularly in true dementia præcox (Gellhorn, 1943 ; Hoskins, 1946). The few schizophrenic patients who showed a response to DFP comparable with that of the manic depressive group were of the paranoid type.

It is difficult to advance an explanation for the marked differences between the two psychotic groups in blood pressure response. By contrast no changes in blood pressure were seen in the normal subjects ; this confirms the observations of Grob and others $(1947 a)$. These blood pressure changes are not likely to have been related to the mental changes produced by the drug, since a fall in blood pressure was not confined to those manic depressive patients showing improvement, and a rise in blood pressure occurred in schizophrenic patients who showed no activation of the psychosis. The fall in blood pressure in the manic depressive patients is in conformity with the observations already made that such patients show increased sensitivity to parasympathomimetic drugs, e.g. mecholyl (Funkenstein and others, 1949; Altman and others, 1943). It is more difficult to interpret the rise of blood pressure in schizophrenic cases, since there is also evidence that these patients are more sensitive than normal to pilocarpine, eserine, and mecholyl (Dawson, 1923 ; Altman and others, 1943 ; Grinevie, 1929). The fact that pallor and fluid retention were concurrently observed during DFP treatment provokes the suggestion that the pressor effect seen in the schizophrenic patients may be due to the release of posterior pituitary hormone. Indeed there is some experimental evidence that DFP has an action on the hypothalamus (Pickford, 1948). Such an explanation, however, does not satisfactorily account for the depressor effect seen in the manic depressive group.

\section{Electroencephalographic Changes}

For these studies a three channel Grass electroencephalograph was used. The time constant was

$0 \cdot 2$, and comparable high frequency filters were used throughout. Half-hour recordings were made using bipolar leads. The subjects were recumbent in a lighted room. In each instance capillary blood was taken for blood sugar estimations, and the effect of three minutes' voluntary hyperpnœa was recorded.

Psychotic Patients.-Resting records of all the psychotic patients were within normal limits. After the administration of DFP certain characteristic changes were observed, the nature of which depended on whether the record was taken within approximately 24 hours (" early ") or later than 24 hours ("late ") after the last injection of the drug.

In " early" records the characteristic picture con- 
sisted of generalized lowering of amplitude with a corresponding diminution in the amount and spread of alpha activity (Fig. 4). In about half the cases irregular low voltage slow activity at 4 to 7 cycles per second (theta frequency) appeared intermittently (Fig. 5). Such activity was most marked in the temporal and central areas but usually also appeared in frontal and occipital leads. It was invariably more marked on the left side and tended to occur in those cases whose original records, though normal,showed slightly more than average activity at theta frequency. Particularly in records showing such increase of slow activity there was increased insta- 음 bility on voluntary hyperpnœa (compared with the $Z_{\mathbb{D}}$ pre-DFP records), the blood sugar levels being comparable (Fig. 6).

In "late" records a markedly different picture $\frac{c}{0}$ emerged. The amplitude was increased beyond that 0 of the original record and this was associated with increased dominance and spread of the alpha rhythm. The slow activity was increased in amount and amplitude and tended to be of lower frequency, 2 to 7 cycles per second, (Fig. 7). The instability on $\vec{B}$ hyperpnœa was further increased (Fig. 8).

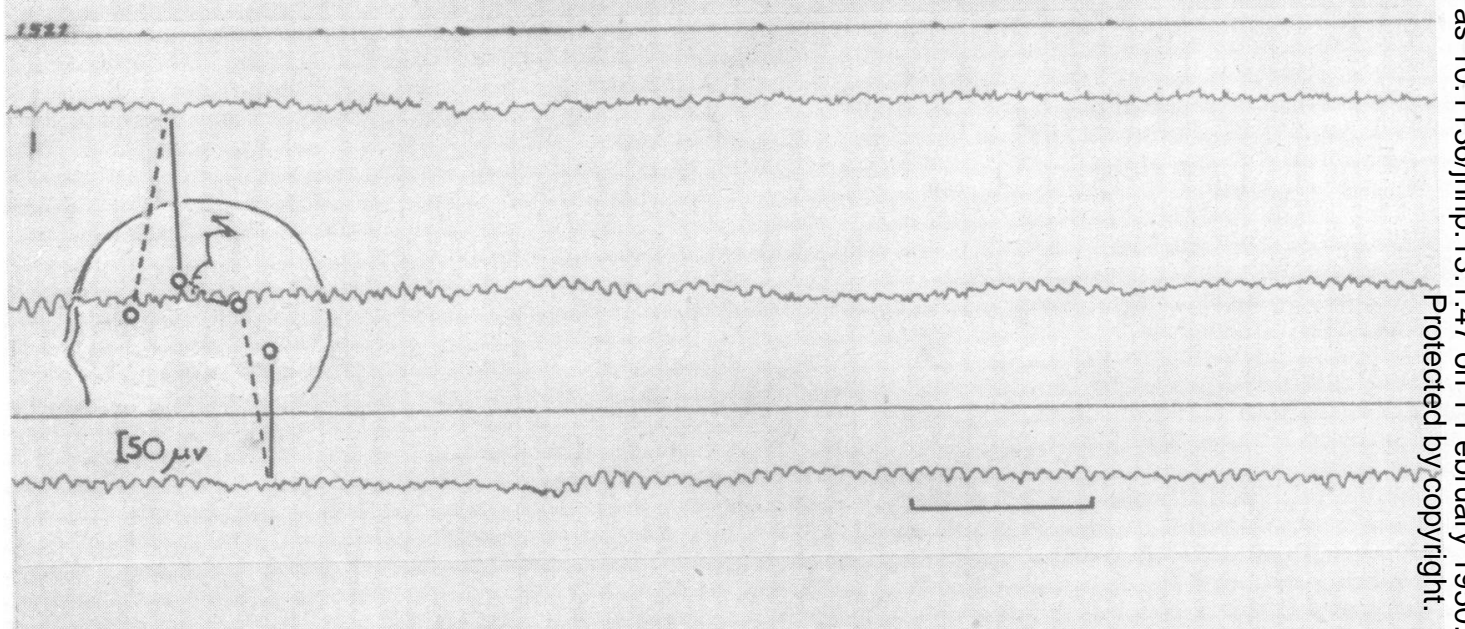

[so $\mu$ v.

FIG. 4.-Lowering of amplitude, reduction in the amount of alpha activity, and lowering of frequency of alpha rhythm : Left frontal, temporal and occipital antero-posterior leads. Time interval marked $=1$ second. (1) Before DFP alpha frequency 10
after $11 \mathrm{mg}$. DFP in seven days. Alpha frequency 8 cycles per second.

(2) Twelve hours 


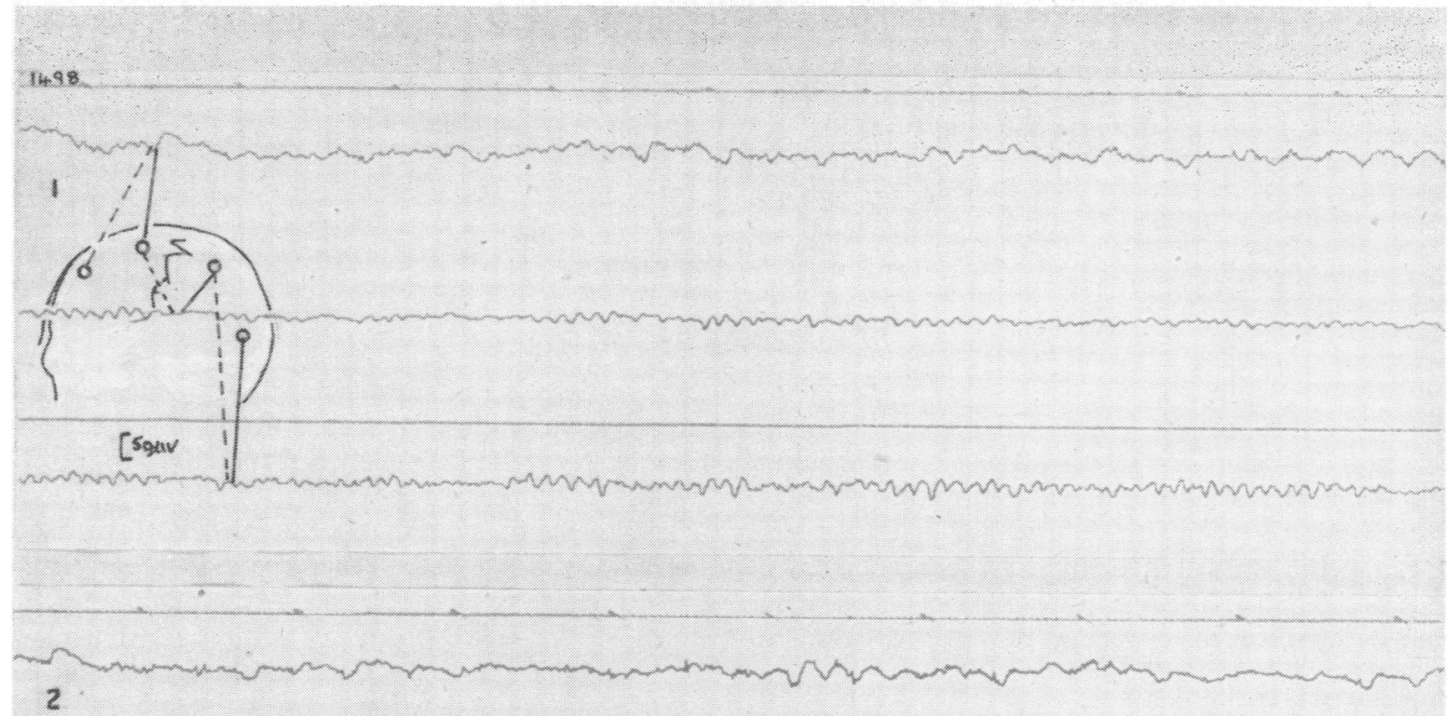

[5oar

Fig. 5.-Left parasagittal antero-posterior positions. (1) Before DFP. (2) Twelve hours after $13 \mathrm{mg}$. DFP. Slow activity at 4 to 5 cycles per second. This is the highest amplitude slow activity obtained in "early" records. (In (1) the apparent slow activity in the frontal lead is due to eye movement artefact.)

A decrease in the frequency of the alpha rhythm by as much as 2 cycles per second was commonly observed; this was present in the majority of records whether " early" or "late," and occurred equally in the two psychotic groups.

All these changes usually disappeared within seven days of the last injection.

In general the EEG changes were much more marked in the manic depressive than in the schizophrenic patients, particularly in the appearance of slow activity (Table V). The records of the four schizophrenic patients who received the drug for a longer period eventually showed slowing of alpha rhythm, lowering of amplitude, and increased theta activity.

Normal Subjects.-In spite of the lower dosage of DFP and lesser cholinesterase inhibition, the same characteristic EEG patterns emerged in these subjects as in the psychotic patients. In the records of all six cases there was a lowering of alpha frequency. All " early" records showed a lowering of amplitude, which in only one case persisted beyond the 24-hour period. The "late" records showed a characteristic increase in amplitude. Slow activity, most marked in both post central areas, was evident, particularly in "late" records, but the response to hyperpnœa was increased in only two subjects. There was no increase in fast activity.*

In an attempt to administer a total dosage of DFP comparable with that given to the psychotic

* In one of these subjects (aged 41) preliminary EEGs showed generalized bilaterally synchronous slow activity at 7 cycles per second. Frequent, paroxysmal bursts of bilaterally synchronous high voltage 3-5 cycles per second activity increasing in amplitude and decreasing in frequency were associated with high voltage fast activity and "sharp waves." There was gross instability on hyperpnca. The appearances were considered to be strongly suggestive of epilepsy. In this case the " early" record ex was mus more " " was mixh " " no mixed fast and slow discharges. a considerable increase in generalized theta activity and some return
of the paroxysmal activity. 
TABLE V

INCIDENCE OF MAIN EEG CHANGES

\begin{tabular}{|c|c|c|}
\hline & $\begin{array}{c}\text { Manic } \\
\text { Depressives } \\
(9 \text { cases })\end{array}$ & $\begin{array}{l}\text { Schizo- } \\
\text { phrenics } \\
\text { (13 cases) }\end{array}$ \\
\hline $\begin{array}{r}\text { Lowering of alpha fre- } \\
\text { quency } \ldots\end{array}$ & 7 & 11 \\
\hline Changes in amplitude and & & 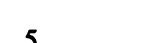 \\
\hline $\begin{array}{l}\text { alpha dominance } \\
\text { Slow activity } \quad \ldots\end{array}$ & 8 & 2 \\
\hline $\begin{array}{c}\text { Increased instability } \\
\text { hyperpnœa }\end{array}$ & 6 & 1 (6 cases) \\
\hline
\end{tabular}

patients, atropine was administered in conjunction with DFP to four additional normal subjects. As a preliminary measure atropine sulphate was administered subcutaneously to these subjects in doses of 0.8 to $5.0 \mathrm{mg}$., and a total of 14 EEG records was taken covering the period from 15 minutes to 4 hours after an injection.

The most characteristic effect of atropine on the EEG closely resembled the appearances produced by the early stages of sleep (Fig. 9). At the beginning of the records there was often a slight increase in amplitude, but almost invariably (in 13 of 14 records) there developed a gradual, but intermittent lowering of amplitude and increase in irregular slow activity. Occasionally this was associated with subjective drowsiness, but more frequently the subjects strongly denied drowsiness and the abnormality remained when the eyes were opened and during the early stages of hyperpnœa when the subject was presumably alert. Occasionally the slow activity was present without decrease in amplitude, and was interspersed with normal alpha rhythm. In the majority of records the alpha frequency was increased to $\frac{1}{2}$ to $1 \frac{1}{2}$ cycles per second. There was no marked change in the response to hyperpnoa, though with high doses there was usually a slight increase in instability.

DFP was then administered daily, atropine being given concomitantly in doses of up to $5 \mathrm{mg}$. Two subjects tolerated $13 \mathrm{mg}$. DFP, one $11 \mathrm{mg}$., and the remaining subject developed an intercurrent infection after $7 \mathrm{mg}$. when the drug was discontinued. During
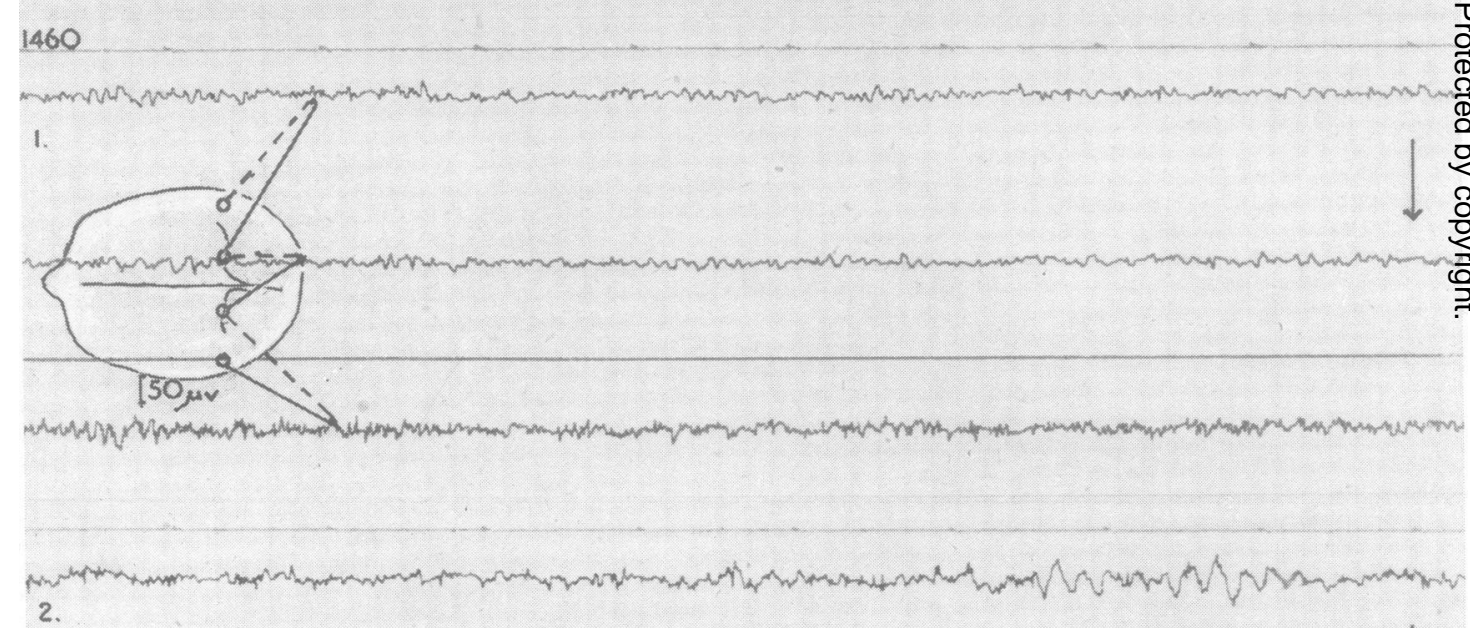
2.
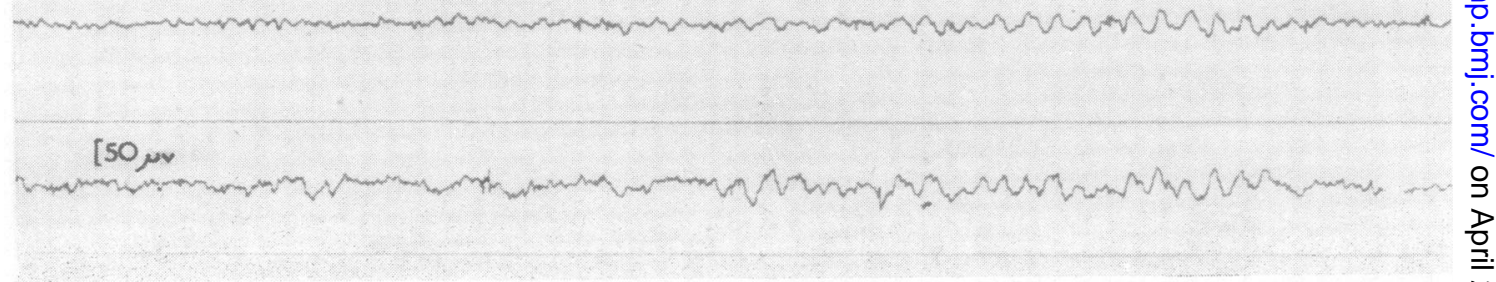

FIG. 6.-Response to hyperpnca in " early" record : Transverse temporo-central leads. Arrow indicates end of 3 minutes voluntary hyperpnca. (1) Before DFP (blood sugar $120 \mathrm{mg}$.). $13 \mathrm{mg}$. DFP in seven days (blood sugar $121 \mathrm{mg}$.). Patient aged 37 years.

(2) Instability eight hours after 
the period of administration of the two drugs the EEG showed the changes characteristic of DFP. The effect of withdrawing both drugs was similar to that seen in the "late" records after DFP alone, but was more marked and persisted for at least 10 days.

\section{Discussion}

The fall and subsequent rise in amplitude were the most characteristic effects of DFP on the EEG. We have also observed marked lowering of amplitude in a small series of myasthenic patients under long-term treatment with DFP (1-2 mg. twice weekly). In the records of all our cases (psychotic, normal, and myasthenic) these findings were considerably more striking than the occasional appearance of slow activity. Grob and others (1947b) also reported an increase in potential after DFP, but do not appear to have observed a preliminary decrease in amplitude.

Lowering of amplitude of the electrocorticogram has been produced in animals by local application of DFP to the cortex, by intravenous injection, and also by intracarotid injection of the drug in doses insufficient to produce systemic effects (Hyde and others, 1949 ; Wescoe and others, 1948 ; Freedman and others, 1949). Acetylcholine, when applied locally to the cortex, may produce convulsive spikes (Brenner and Merritt, 1942), but these are often preceded by a period of cortical depression ; indeed depression of cortical activity may be the only phenomenon observed (Forster and others, 1946 ; Bornstein, 1946). The analogy between these findings and our EEG results is striking and
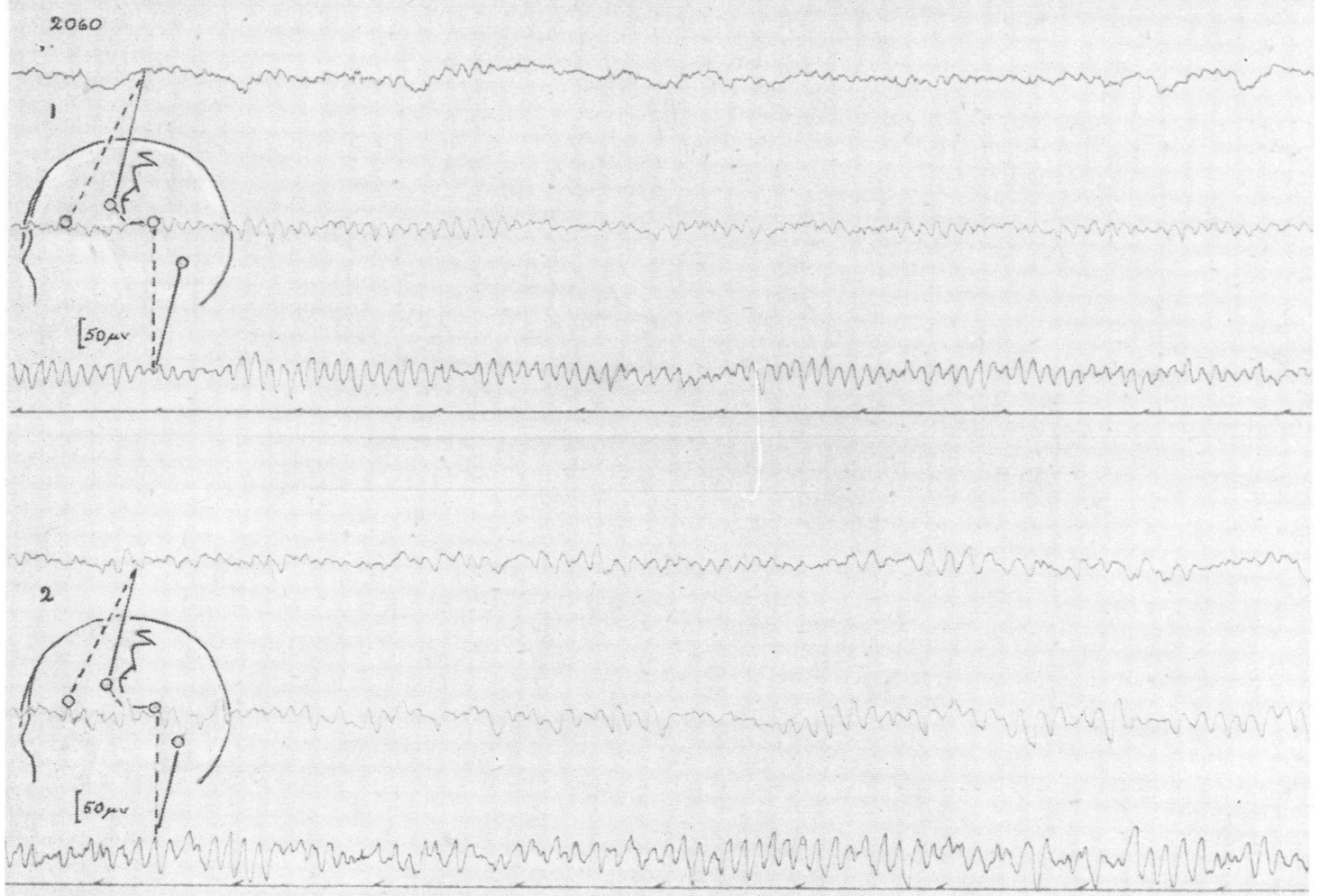

FIG. 7.-Typical appearance of "late" record : Left frontal, temporal and occipital antero-posterior leads. (1) Before DFP. (2) Forty-eight hours after last injection of DFP. Alpha rhythm shows increase in amplitude and is of lower frequency. Irregular, moderate voltage slow activity ( 2 to 7 cycles per second) is seen in all leads. 
suggests the possibility that the changes in amplitude may be related in some way to the anticholinesterase effect of DFP in the brain.

On the other hand the systemic effects of DFP, in particular its action on the cardiovascular system, must be carefully considered in relation to these EEG changes. There is evidence that cerebral vasodilation can be produced by parasympathetic stimulation, by acetylcholine or by eserine (Popesco, 1945 ; Baruk and others, 1948 ; Chorobski and Penfield, 1932 ; Cobb and Finesinger, 1932 ; Miller and others, 1940). Furthermore an association has been established between cerebral vasodilation and depression of cortical activity (Leao, 1944 ; Darrow and others, 1944). Similarly, cerebral vasoconstriction, shown to be produced by adrenalin and by sympathetic stimulation may be associated with increased cortical potential (Forbes and others, 1933 ; Popesco, 1945 ; Darrow and others, 1942). The relatively rapid reversal of the cortical depression in our cases is possibly more readily explained by a mechanism of this nature than by changes in the cholinesterase activity of the brain.

The possibility that the lowering of amplitude was due to anxiety is excluded since, although the drug produced mental depression, there was no evidence of any increase in anxiety in our subjects.

Grob and others (1947b) reported the appearance of " slow waves ( 3 to 6 per second) of high voltage, usually most marked in the frontal leads ... similar to those seen in patients with grand mal epilepsy." In our " early" records the slow activity was of low
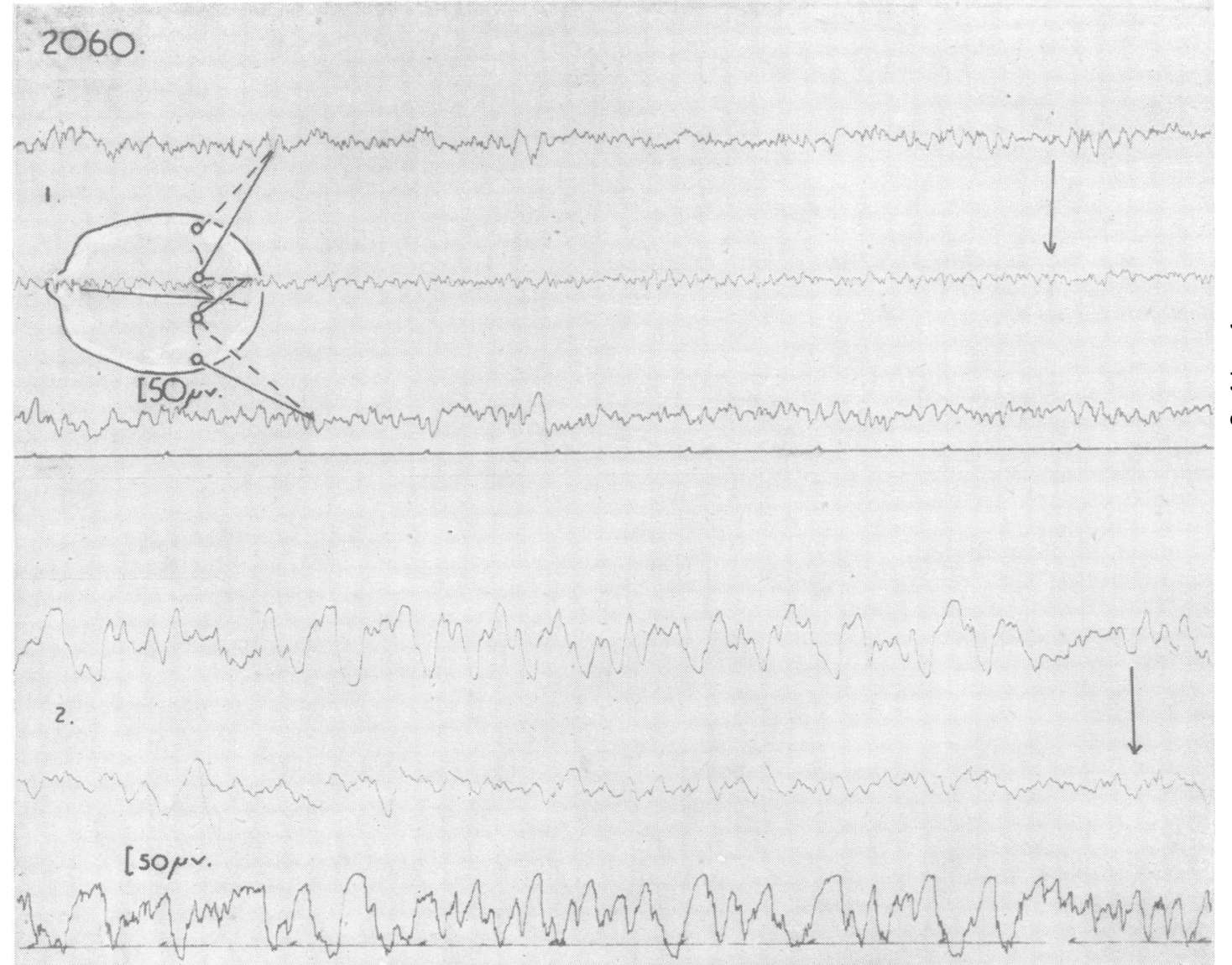

Fig. 8.-Response to hyperpnœa in "late" record : Same case as Fig. 7. Transverse temporo-central leads. Arrow indicates end of three minutes' voluntary hyperpncea. (1) Before DFP. (2) Forty-eight hours after last injection of DFP. 
voltage and occurred infrequently, and there was no finding which could be interpreted as suggesting an epileptogenic action of the drug (see also footnote page 53). In the "late" records, although the slow activity was of higher voltage, it was irregular, did not occur paroxysmally, and was not associated with high voltage fast activity.

It is not possible from the available evidence to decide whether the slow activity is to be attributed to cholinesterase inhibition, vascular changes, or to some other effect of the drug such as fluid retention. There was no direct relationship between the degree of inhibition of red cell cholinesterase and the incidence of slow activity in different cases.

Lowering of alpha frequency occurs in such a wide variety of conditions in which cerebral metabolism is disturbed that it is difficult to assess its significance in our cases. It may possibly have been due to vascular changes, and is in contrast with the increase in alpha frequency which occurred after the administration of atropine.
The remarkable resemblance of the effect of atropine on the EEG to that of the early stages of sleep has been previously reported by Gibbs and others (1937). These authors also emphasized that their subjects were not drowsy ; in fact in a number of our cases atropine produced a state of mild euphoria and excitement. Despite the large doses of atropine used it was not possible to counteract completely either the systemic effects of DFP or its effects on the EEG. It is not clear whether the pronounced EEG change on withdrawing both drugs is related to the previous administration of atropine or to the higher dosage of DFP used in these normal subjects.

\section{Mental Changes}

Psychotic Patients.-In 12 patients, whose case records are presented in the appendix, significant mental changes occurred which were different in the two psychotic groups.

In 6 of the 17 schizophrenic patients a most

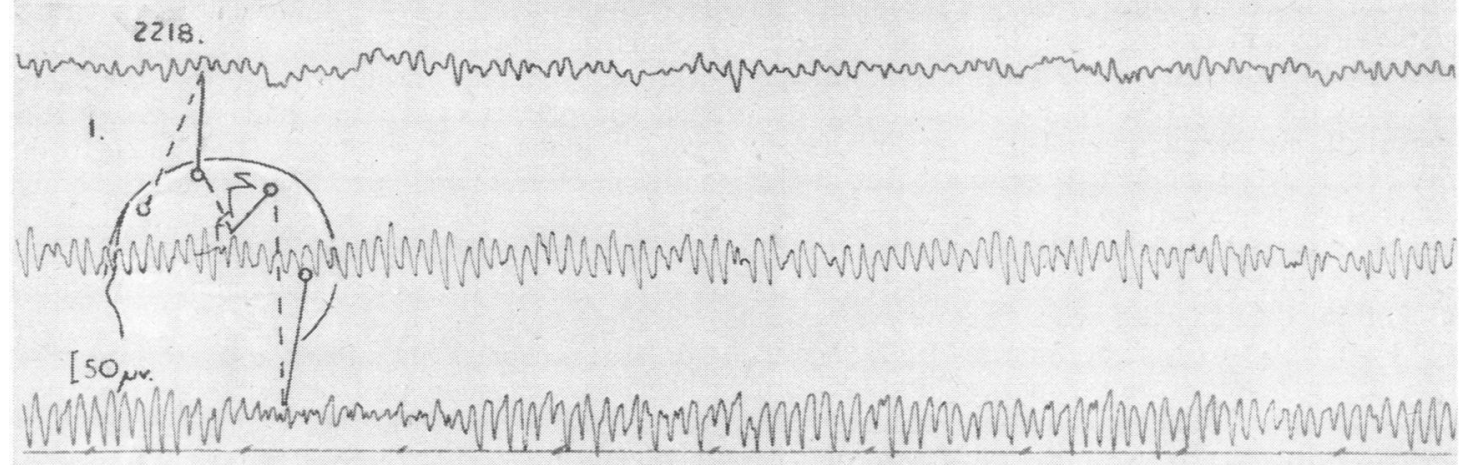

$[50 \mu v$.

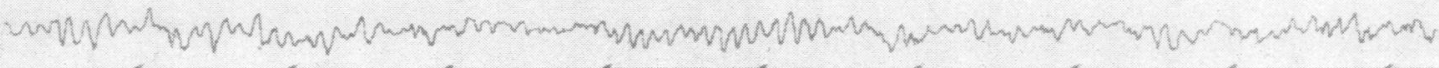

Fig. 9.-Left antero-posterior parasagittal leads. (1) Before atropine. (2) One hour after $2.5 \mathrm{mg}$. atropine, subject not drowsy. 
pronounced mental effect was observed. This consisted of an "activation" of the psychosis, or the reappearance in chronic cases of the florid symptoms which had characterized the onset of the illness. Bizarre behaviour, thought disorder, ideas of reference, and aural hallucinations were increased, without evidence of impairment of consciousness. These changes persisted for a number of months after the withdrawal of DFP. One schizophrenic case (E. O'C.) showed marked improvement which was associated with diminution of anxiety. In the remaining 10 schizophrenic cases no significant mental changes were observed.

Of the manic depressive group, the two cases who were mentally normal at the time of the administration of the drug showed only slight mental changes which were comparable to those observed in normal subjects. Both patients complained of sleeplessness and increased dreaming; in one the dreams were unusual and fascinating, in the other they were nightmares. One was also slightly depressed, truculent, and abrupt in speech. All these symptoms disappeared after the withdrawal of the drug.

Two of the six hypomanic cases were unaffected by the drug and one of these three months later developed a moderately severe depression. In the remaining five cases (four hypomanic and one depressed) significant mental changes occurred, which indicated a marked depressant effect of the drug. Two hypomanic patients (C.R. and A.B.) improved considerably during administration of DFP and thereafter recovered completely. One case of hypomania with schizophrenic symptoms (A.J.) received two separate courses of DFP and showed, on both occasions, marked improvement during the period of administration of the drug, but relapsed when the drug was withdrawn. One patient (R.B.), who suffered from recurrent mania, but was almost normal before and during administration of DFP, became maniacal two days after its withdrawal, and remained so for four weeks. In the one depressive case (V.F.) a profound deepening of the depression occurred during administration of DFP.

Normal Subjects.-In these subjects a very characteristic mental picture of depression, irritability, - lassitude, and apathy appeared even before the onset of unpleasant physical symptoms. They looked dejected and felt unhappy. Their activity was retarded, and they talked little and despondently. There was a diminution, rather than an increase, of tension ; they developed a " don't care" attitude, lost interest and concern for the feelings of others, and at times were markedly irritable. The depression was associated with a slowness, or poverty of thought, without disturbance of orientation, memory, or intellectual ability. Raven's matrices tests before and during the administration of DFP indicated a considerable increase in the time necessary to complete the test, but no significant change in actual score. In addition a number of other symptoms were observed which have also been reported by Grob and others $(1947 b)$. These were lassitude by day, and insomnia and restlessness at night, with excessive dreaming. The emotional lability and tremor reported by these authors were not common in our patients, and paraesthesias and visual hallucinations did not occur.

Atropine in doses of 1 to $5 \mathrm{mg}$. produced quite a marked euphoria. It also partially counteracted the depressant effect of DFP.

\section{Discussion}

In the schizophrenic cases showing activation of the psychosis the change in the clinical picture was profound. A number of facts show that this effect was not a form of delirium. Disturbances of orientation were not marked ; the mental state produced was characteristic of the psychosis and of each patient's early symptomatology; EEG records did not show the effects characteristic of delirium; and the mental changes persisted long after the physical symptoms had subsided. It is possible that the activation may be related to the anticholinesterase action of the drug on the brain. This effect, however, is in direct contrast to the improvement in schizophrenic subjects produced by intravenous injections of acetyl choline as reported by Fiamberti (1946).

In manic depressive patients, and also in normal subjects, depression was undoubtedly the most characteristic mental change produced by DFP. It will be seen from our case records that the depression was not due merely to the presence of unpleasant physical symptoms. It is also evident that the opposite effect may be produced by withdrawing the drug (Cases R.B., A.J.). Our findings suggest that DFP may possibly be of therapeutic value in some manic patients if it is given in repeated small doses and withdrawn gradually after improvement has been obtained.

\section{Summary and Conclusions}

In 17 schizophrenic patients, 9 manic depressive patients and 10 normal subjects, the effects of DFP given intramuscularly in doses of 1 to $2 \mathrm{mg}$. daily have been studied. Observations have been made of the effect of the drug on the cholinesterase activity of the blood, and on the physical and mental state of the patients. Electroencephalographic studies have also been carried out. The mean values for red cell and plasma cholinesterase activity obtained before 
DFP treatment were not significantly different in the three groups of subjects. Administration of the drug produced marked inhibition of both types of cholinesterase activity, and the levels of inhibition were comparable in the two psychotic groups.

When DFP was administered for a period of seven days in a total dosage of $13 \mathrm{mg}$. characteristic physical effects were produced, particularly on the gastrointestinal tract and on the cardiovascular system. These were considerably less marked in schizophrenic than in manic depressive and normal subjects. There was a marked difference in the blood pressure responses of the two psychotic groups. The possible significance of these findings is discussed.

A number of electroencephalographic changes are described, the most characteristic of which is lowering of amplitude associated with diminution of alpha activity. Approximately 24 hours after the withdrawal of DFP, however, an increase of amplitude with increased dominance and spread of the alpha rhythm was seen. No evidence of an epileptogenic action of the drug was observed. The incidence of EEG changes was much greater in normal and manic depressive subjects than in schizophrenic subjects. Atropine in doses of 1-5 mg. subcutaneously, produced changes in the EEG almost indistinguishable from those of the early stages of sleep and did not counteract the effects of DFP on the EEG.

The mental changes produced by the drug are illustrated by case records (appendix). A characteristic depressive effect was observed in manic depressive patients and in normal subjects. In a number of schizophrenic patients, on the other hand, an activation of the psychosis occurred which was not associated with disturbances of consciousness.

It is a pleasure to acknowledge the cooperation we have received from Dr. G. A. Lilly and the staff of Cane Hill Hospital, and from Surgeon Captain A. Fairley of Porton Experimental Establishment. We are also grateful to Dr. Denis Hill for his advice in the electroencephalographic studies, to Mr. A. R. Jonckheere for the statistical analysis of results, and to Miss Honor Geoghegan for assistance in the cholinesterase estimations.

Part of the expenses of this work was defrayed by a grant from the Ministry of Supply.

\section{REFERENCES}

Adrian, E. D., Feldberg, W., and Kilby, B. A. (1947). Brit. J. Pharmacol., 2, 56.
Altman, L. L., Pratt, D., and Cotton, J. M. (1943). J. nerv. ment. Dis., 97, 296.

Baruk, H., David, Racine and Vallancien (1948). Rev. neurol., 80, 497.

Bornstein, M. B. (1946). J. Neurophysiol., 9, 349.

Brazier, M. A. B. (1948). J. Neurol. Neurosurg. Psychiat., $11,118$.

Brenner. C., and Merritt, H. H. (1942). Arch. Neurol. Psychiat., Chicago, 48, 383.

Chorobski, J., and Penfield, W. (1932). Ibid., 28, 1257.

Cobb, S., and Finesinger, J. E. (1932). Ibid., 28, 1243.

Darrow, C. W., Green, J. R., Davis, E. W., and Garol, H. W. (1944). J. Neurophysiol., 7, 217.

-_, Jost, H., Solomon, A. P., and Mergener, J. C. (1942). J. Psychol., 14, 115.

Dawson, W. S. (1923). J. ment. Sci., 69, 182

Engel, G. L., Romano, J., Ferris, E. B., Webb, J. P., and Stevens, C. D. (1944). Arch. Neurol. Psychiat., Chicago, 51, 134.

Fiamberti, A. M. (1946). Riv. Pat. nerv. ment., 66, 1.

Forbes, H. S., Finley, K. H., and Nason, G I. (1933). Arch. Neurol. Psychiat., Chicago, 30, 957.

Forster, F. M., Borkowski, W. J., and McCarter, R. H. (1946). J. Neuropath. exp. Neurol., 5, 364.

Freedman, A. M., Bales, P. D., Willis, A., and Himwich, H. E. (1949). Amer. J. Physiol., 156, 117.

Funkenstein, D. H., Greenblatt, M., and Solomon, H. C. (1949). Amer. J. Psychiat., 106, 16.

Gellhorn, E. (1943). "Autonomic Regulations" Interscience, New York.

Gibbs, F. A., Gibbs, E. L., and Lennox, W. G. (1937). Arch. intern. Med., 60, 154.

Grinevie, V. (1929). Zbl. Neurol., Psychiat., 51, 680.

Grob, D., Lilienthal, J. L., Harvey, A. M., and Jones, B. F. $(1947(a))$. Bull. Johns Hopk. Hosp., 81, 217.

, Harvey, A. M., Langworthy, O. R., and Lilienthal, J. L. (1947(b)). Ibid., 81, 257.

Hoskins, R. G. (1946). "The Biology of Schizophrenia." W. W. Norton, New York, Chapman and Hall, London.

Hyde, J., Beckett, S., and Gellhorn, E. (1949). J. Neurophysiol., 12, 17.

Jones, M. S., and Stadie, W. C. (1939). Quart. J. exp. Physiol., 29, 63.

Leao, A. A. P. (1944). J. Neurophysiol., 7, 359.

McCombie, H., and Saunders, B. C. (1946). Nature, Lond., 158, 382.

Mackworth, J. F., and Webb, E. C. (1948). Biochem. J., 42, 91.

Mendel, B., Mundell, D. B., and Rudney, H. (1943). Biochem. J., 37, 473.

Miller, F. R., Stavraky, G. W., and Woonton, G. A. (1940). J. Neurophysiol., 3, 131.

Pickford, M. (1948). Brit. med. J., 2, 169.

Popesco, M. (1945). Bull. Acad. Méd. Roumanie 17, 10.

Randall, L. O., and Jellinek, E. M. (1939). Endocrinology, 25, 278.

Richter, D., and Lee, M. (1942). J. ment. Sci., 88, 435.

Tod, H., and Jones, M. S. (1937). Quart. J. Med., n.s. 6, 1 .

Wescoe, W. C., Green, R. E., McNamara, B. P., and Krop, S. (1948). J. Pharmacol., 92, 63. 


\section{A P P E N D I X}

\section{Schizophrenic Group}

Case G.P.-This patient was a man aged 38, with paranoid schizophrenia of onset in 1938.

A quiet, meticulous, highly imaginative child, G.P. was always the butt of family ridicule and dependent on his mother. On leaving school in the top class he made few friends of either sex and was unable to keep a permanent job. On the death of his mother in 1939 he turned to spiritualism and formed a strong homosexual attachment. Gradually he developed mild ideas of reference centred on his femininity, and by 1942 he had developed delusions of persecution and ideas of influence by spirits which provoked aggressive outbursts. By day he was garrulous, self-assertive, sarcastic, and resentful ; at night he could not sleep and walked about talking to himself. $\mathrm{He}$ was admitted to hospital in May, 1944, by which time his conversation had become grossly disconnected and it was evident that he was aurally hallucinated. During the past four years the overt hostility and resentfulness had gradually disappeared; he had become dull, apathetic, and slightly perplexed but automatically obedient. Intermittently he made attempts to mutilate himself. His conversation, although considerably more coherent was still disconnected, wandering, evasive, superficial, and mainly concerned with requests for transfer.

PATIENT : "I've had a lot of torment, a terrific amount of torment, but I've managed to keep my senses and still know what I'm supposed to do, Sir. It's so embarrassing. I'll have to ask you again . . . . People I've known come here trying to get me away . . . . It's only so local people can find me. Could I have a transfer, please ?"

In March, 1948, he received $13 \mathrm{mg}$. DFP over the course of seven days. Nausea and later vomiting were severe, and auricular fibrillation developed without evidence of cardiac failure. On the sixth day a marked mental change was evident. He became extremely restless, crawling under his bed, complaining that it was moving up and down, banging his head with his fists and knocking it against the wall. He passed fæces in his bed and smeared them over himself, tore off his clothes and stood naked, adopting strange postures. His speech became rapid and grossly incoherent.

PATIENT: "Please say what you have to say .... . lend me a fag ..... don't leave .... . let's play fair .... for bread .... sit on the floor .... I'll sit on the floor.... they do know without being shown .... there's no Disraeli .... I don't want anything at all .... . why don't you play fair ..... thank you, Sir .... thank you for a wonderful life .... a suit of clothes and I can walk out.... thank you, God."

Questioning had little influence on this babble of phrases and his replies were mainly irrelevant. His usual perplexity was greatly accentuated; he became anxious, bewildered and frightened, frequently pleading for help. His attitude to the male nurses was overtly homosexual. There was no objective evidence of visual hallucinations. Assessment of his state of consciousness was difficult, but he seemed to know that he was in a hospital ; he commented on recent events in the ward and did not misname the medical staff. His EEG remained normal throughout.

After the withdrawal of the drug there was some gradual improvement in the degree of thought disorder, but for at least eight months the patient has remained anxious, depressed, and in a state of fluctuating excitement, dirty, mutilating himself, and tearing bedclothes.

Case R.G.-This patient was a man aged 32 with hebephrenic schizophrenia of onset in 1942.

R.G. was of average intelligence and a pleasant shy disposition, and had worked satisfactorily as a low paid clerk. In 1942 he sustained a severe gunshot wound of the arm. Two months later, during convalescence, it was noted that he was apathetic, childish, and manneristic. He developed delusions of persecution, lost all insight, and pulled the dressings off his wound. He was invalided home and on his admission to hospital in 1943 he was untidy, wetting himself, and dribbling. His behaviour was strange ; he was distractible, off-hand, restless, fidgety, and manneristic. He laughed foolishly and talked incoherently, was apathetic, aurally hallucinated, and almost inaccessible.

Over a period of years he gradually became brighter, more accessible and alert. His habits improved and he did some ward work. He was able to put up a good social front, conversing readily but with extreme superficiality and loss of conceptualization. When on his own he giggled occasionally, swore to himself, and wrote cryptic phrases on books and magazines.

This patient received $47 \mathrm{mg}$. DFP in 35 days. After $30 \mathrm{mg}$., when the inhibition of red cell plasma and cholinesterase activity was $69 \%$ and $99 \%$ respectively, he became increasingly restless, and his behaviour (punching out, shouting, and sudden impulsive behaviour) suggested an increase in aural hallucinations. He neglected himself and passed urine and fæces in his bed. He was negativistic, truculent, irritable, and aggressive. His accessibility diminished and his speech became less coherent and more repetitive. He laughed frequently and inappropriately. (His EEG at this time showed only minimal abnormalities.) This state of severe deterioration persisted for $\mathbf{1 5}$ to 20 days after the withdrawal of DFP when he gradually returned to his previous condition.

Case B.G.-This patient was a man aged 38 with paranoid schizophrenia of onset in 1940.

In this patient "process" symptoms developed insidiously on the basis of an eccentric schizoid personality. For the past four years he had been silent, withdrawn, immobile, and automatically obedient. During a long course of DFP, episodes of truculence, negativism and paranoid complaining occurred which were associated with periorbital œdema. These episodes persisted for several months after DFP therapy, gradually becoming less frequent. 
Case G.H.-This patient was a man aged 40 with paranoid schizophrenia of onset in 1927.

At first aggressive, deluded, and aurally hallucinated this patient had been for 10 years in a state of catatonic immobility, silent, and inaccessible. After DFP injections he became more active, excited, and impulsive. His shouting and aggressive behaviour suggested increased aural hallucinations. He returned gradually to his previous state six months after DFP treatment.

Case J.F.-This patient was a man aged 36 with hebephrenic schizophrenia of onset in 1941 .

Throughout his illness he had been silly, grimacing, muttering, and constantly hallucinated. At first he had frequent episodes of excited destructiveness, but these had not occurred during the last four years. After DFP therapy he showed bizarre over-activity, aimless wandering, incoherent chattering, hostility and destructiveness. Eight months later he had returned to his previous state.

Case R.R.-This patient was a man aged 40 with simple schizophrenia of onset in 1930.

During his long illness he had gradually become quiet, inactive and inaccessible, but tidy and cooperative. Several weeks after DFP therapy he showed rapid deterioration in habits; he became dirty, slovenly, and dribbled from the nose and mouth. Eight months later there was no evidence of improvement.

Case E.O'C.-This patient was a man aged 38 with hebephrenic schizophrenia of onset in 1937.

Facile, inert, and apathetic, he was a ravenous eater who stole other patient's food. He was an erratic and dilatory ward worker. His answers to questions were brief and irrelevant. Since triazol treatment in 1938, which was stopped because of extreme terror, he had shown objective signs of anxiety (tachycardia, sweating, dilated pupils, increased deep reflexes) particularly in the presence of doctors. After $13 \mathrm{mg}$. of DFP this response had largely disappeared, he talked readily, often spontaneously, though with marked thought disorder. He became an industrious and reliable worker, joined a patients' social club, played whist, and was careful of his appearance. Eight months later he was still in this improved state although the somatic manifestations of anxiety were returning.

\section{Manic Depressive Group}

Case C.R.-This patient was a woman aged 54 with recurrent mania of onset in 1927.

Her father, brother, and uncle are manic depressive. She has had three attacks of mania each lasting four to six months and for some years has been in partial remission, remaining elated, talkative, truculent, and unreliable. The last attack began four weeks before the administration of DFP. She was elated, winking, grinning, singing, and gesturing. Her behaviour was absurd and uncontrolled; she was erratic and incalculable and expressed delusions of persecution. After two weeks she had settled into a state of hypomania ; she was still elated, unpredictable, occasionally resistive and continuously laughing and talking at the time of the investigation. During the administration of DFP she became more composed and after the withdrawal of the drug she showed gradual further improvement, gained insight, became sober in behaviour and speech and was discharged from hospital three weeks later (i.e., 10 weeks after the onset of the attack). She has since remained well and her husband reports that she is much calmer than in previous recoveries and appears to have completely regained her normality.

Case A.B.-This patient was a woman aged 38 with acute mania with schizophrenic symptoms of onset in 1948.

A lively but rather intolerant, dogmatic extrovert of pyknic build, this patient had a distinguished academic career bəfore her marriage 10 years ago. Her illness began six weeks before the investigation with depression and irrational fears followed by over-activity, rather bizarre bəhaviour, talkativeness, paranoid ideas, ideas of influence, feelings of passivity, and aural hallucinations. At the time of the investigation, although the rather bizarre paranoid delusions were less evident and there was no typical schizophrenic thought disorder, she was still hypomanic, talked loudly and continuously and was elated, impatient and grandiose.

During and after the administration of DFP she became quieter in speech and more sober in attitude. She gained insight into her delusions and was able to discuss sensibly the nature and possible causes of her illness. There remained a slight quaintness of ideation, circumstantiality, egotism and unwarranted exuberance which diminished sufficiently for the patient to be discharged from hospital six weeks after the withdrawal of DFP and 13 weeks after the onset of her illness. Her improvement continued and for ten months she has been mentally normal.

Case A.J.-This patient was a woman aged 27 with recurrent mania with schizophrenic features; onset, 1939.

She was a bright, demonstrative, histrionic extrovert of asthenic build. Her first attack lasted seven months and after prolonged narcosis she recovered completely for six years. Her second attack in July, 1946, was temporarily relieved by E.C.T. but she relapsed two months later. In September, 1947, there was a gradual swing to depression, followed by a rapid return to a maniacal state in October, 1947.

Six months later, at the time of the investigation she was over-active, interfering, distractible, and constantly talking in an over-familiar manner with marked flight of ideas. Her speech was fragmentary to the point of incoherence with occasional symbolizations. She was fatuously elated and expressed ill-formed bizarre delusions largely of a somatic nature.

During the administration of DFP a marked sobering effect was observed. Her talk was less rapid and more coherent, but there was some poverty of thought. ("Muscarinic" symptoms at this time were moderately severe.) On the withdrawal of DFP she immediately returned to her previous state of hypomania. Two weeks later DFP was given again in daily doses of $1 \mathrm{mg}$., and its administration continued for three weeks. 
No unpleasant " muscarinic" symptoms occurred with this dosage. After $5 \mathrm{mg}$. had been given improvement was again evident ; she became quiet and subdued, but was slightly irritable and verging on depression. Her sleep was deep and unbroken. Her speech was quiet and collected, with some bewilderment but no evidence of distractibility. Her brief, superficial replies to questions, however, indicated a marked poverty of thought, and she was apathetic, disinterested, and lacked ambition. Her mild delusions persisted unchanged.

Within 48 hours of the withdrawal of DFP she returned to a state of mania during which she ran about the ward singing, stripping naked and urinating on the floor. She was again distractible, facetious and mischievous, talking rapidly and disjointedly, and frequently bursting into hilarious laughter. She remained in this state for several weeks and thereafter gradually returned to her previous state of hypomania.

Case R.B.-This patient was a woman aged 51 .

A plump, jolly extrovert, she had her first attack of mania in 1934 following severe marital stress. Since that time increasingly frequent attacks of mania had occurred, sometimes followed by short periods of depression. Although mildly hypomanic between attacks, for the majority of the time she had been able to work for periods of several months as a cook. The attacks of mania were characterized by over-activity, distractibility, talkativeness and affective lability with marked elation, periods of weeping, and irritability. Her talk was irrelevant and consisted of detached and apparently disconnected sentences. Disorientation, aural hallucinations, and paranoid ideas had also been noted. The attacks usually lasted about eight months. The shortest interval between attacks had been 12 months and the last attack ceased two months before the investigation.

Before the administration of DFP the only abnormal features were slight fidgetiness, loquacity, and lability of affect ; her'speech, though rapid, was careful, coherent, and rational. During the course of injections she complained of slight depression, sleeplessness, and nightmares, but there was little objective evidence of mental change.

Two days after the withdrawal of DFP the patient became excited, violent and noisy, screaming and singing, destructive and refusing food. She was euphoric and distractible, garrulous and incoherent, her speech consisting of disconnected phrases. She was disorientated, felt that everything about her was mysterious and misinterpreted identities. There was evidence of aural and visual hallucinations.

This state of maniacal excitement persisted for four weeks after which it gradually abated leaving the patient in a fluctuating hypomanic state slightly worse than before the injections. The EEG at the termination of the course of injections (i.e., two days before the onset of the manic episode) showed lowering of amplitude, a moderate excess of parieto-occipital slow activity and slowing of the alpha frequency. Three weeks after DFP was stopped, when the patient was still severely disturbed, the EEG was normal.

Case V.F.-This patient was a woman aged 48 with involutional depression with paranoid features; onset July, 1947.

She was a plump, cheerful, married woman with two children who had had amenorrhœa for several months before the onset of her illness. Depression, insomnia, lassitude, guilt feelings and religious preoccupation, with mild paranoid ideas were associated with severe loss of weight. Electro-convulsive treatment had been followed by a partial remission lasting 10 weeks. A relapse in January, 1948 was characterized by increasingly severe agitation and depression, and also by suspicion, delusions of persecution, passivity feelings, bizarre somatic delusions, derealization and aural and visual hallucinations of a religious nature. She appeared composed but discussion of her delusional ideas produced weeping, suffusion of the face, agitation and dejection.

During the administration of DFP for one week there was no significant change in her mental condition. A second course of DFP was begun one month later in doses of $1 \mathrm{mg}$. daily. With this dosage no " muscarinic" symptoms occurred. A deepening of the depression soon became obvious. She was continuously agitated, dejected, wept quietly and frequently, neglected herself and refused food. She rarely moved, her speech was limited to one word answers, and she could not sleep without a sedative. She believed she had to die or be tortured, and refused food for this reason. There was no disturbance of orientation and her EEG at this time was normal. The withdrawal of DFP was followed by partial improvement: she was able to get up, took some care of her appearance, and ate more readily. Her condition thereafter remained essentially unchanged. 